\title{
Respiratory Morbidity Associated with Long-Term Occupational Inhalation Exposure to High Concentrations of Hydrated Calcium Sulfate Dust
}

\author{
Masoud Neghab' ${ }^{1}$, Samira Mirzaei Toosi2* ${ }^{*}$ Parisa Azad ${ }^{2}$ \\ ${ }^{1}$ Research Center for Health Sciences, Shiraz University of Medical Sciences, Shiraz, Iran \\ ${ }^{2}$ Student's Research Committee, Shiraz University of Medical Sciences, Shiraz, Iran \\ Email: "samira.toosi1368@yahoo.com
}

Received 15 October 2015; accepted 24 November 2015; published 27 November 2015

Copyright (C) 2016 by authors and Scientific Research Publishing Inc.

This work is licensed under the Creative Commons Attribution-NonCommercial International License (CC

BY-NC).

http://creativecommons.org/licenses/by-nc/4.0/

c) (i) Open Access

\section{Abstract}

Despite wide application of hydrated calcium sulfate, possible respiratory effects of long-term occupational exposure to high concentrations of this chemical have only been investigated in a limited number of epidemiological studies. This study is undertaken to examine this issue, more thoroughly. This cross-sectional study is carried out at a local gypsum plant in Shiraz, capital of Fars province situated in south western Iran. All exposed subjects ( 20 male workers) and 20 healthy non-exposed male individuals as the referent group are investigated. Prevalence of respiratory symptoms among the studied subjects is evaluated and they undergo spirometry test (twice for the exposed group and once for the unexposed employees). Moreover, to assess the extent to which workers are exposed to gypsum dust and using standard methods, inhalable and respirable fractions of this compound are measured in different dusty worksites. Average airborne concentration of inhalable dust fraction is estimated to be $24 \pm 14.76 \mathrm{mg} / \mathrm{m}^{3}$ which is higher than the recommended threshold limit value (TLV) for this chemical. Respiratory symptoms such as phlegm, wheezing and dyspnea are significantly more prevalent in exposed subjects than in non-exposed employees $(p<0.05)$. The results of ventilatory function tests (preshift) don't show any significant differences between both groups. However, some post-shift parameters of ventilatory function such as FVC, FEV1 and FEV1/FVC ratio are significantly lower than those of preshift and referent group. Exposure to high atmospheric concentrations of gypsum dust is associated with a significant increase in the prevalence of respiratory symptoms along with acute reversible significant decreases in some parameters of ventilatory function.

\footnotetext{
"Corresponding author.
}

How to cite this paper: Neghab, M., Toosi, S.M. and Azad, P. (2016) Respiratory Morbidity Associated with Long-Term Occupational Inhalation Exposure to High Concentrations of Hydrated Calcium Sulfate Dust. Occupational Diseases and Environmental Medicine, 4, 1-7. http://dx.doi.org/10.4236/odem.2016.41001 


\section{Keywords}

\section{Gypsum Dust, Occupational Exposure, Respiratory Symptoms, Ventilatory Function Tests}

\section{Introduction}

Gypsum, calcium sulfate dihydrate $\left(\mathrm{CaSO}_{4} \cdot 2 \mathrm{H}_{2} \mathrm{O}\right)$, is a naturally occurring mineral consisting of $79 \%$ calcium sulfate and $21 \%$ water [1]. Gypsum is obtained from heating process of gypsum rock [2]. Calcium sulfate dihydrate is a colorless, solid inorganic substance with hygroscopic properties [3]. The production sources of this substance vary and it may be contaminated with quartz [4]. Workers employed in the processing of gypsum rock may be exposed to high atmospheric concentrations of gypsum dust via inhalation, ingestion, skin and/or eye contact [5]. It is classified as a nuisance dust [4]. Limited information exists as to the respiratory effects of gypsum dust. This, presumably, is due to the general belief that the substance is harmless due to its short half-life (in the order of a few weeks or, at most, months) [4] [6] [7].

Tracheobronchial mucus membrane and upper respiratory tract irritation, laryngitis and sore throat as well as symptoms such as cough and wheezing have been reported as a result of inhalation exposure to this substance [5] [8]-[10]. Reduced lung functional capacities have also been reported as a result of exposure to this substance [11]. Some studies have indicated that gypsum dust after years of extreme exposure is able to produce micronodular opacities in the lungs [12] [13].

In contrast, some epidemiological studies of workers exposed to pure gypsum have not found evidence of any pulmonary illnesses or prevalence of lung fibrosis or pneumoconiosis and, even some authors have introduced calcium sulfate as a protective dust to prevent silicosis [14] [15]. In a study of 241 employees in gypsum mines, results of chest X-rays suggest that observed lung shadows are more prevalent in workers employed in mines with higher quartz concentration than others [16].

It is estimated that more than 13 million tons of gypsum is annually produced in Iran and a large number of workers are occupationally exposed to this substance in mines, furnaces, construction, etc. [17]. Although, gypsum dust is classified as a nuisance dust and apparently, causes a benign pneumoconiosis [18]. Limited information exists as to the respiratory health of workers following long term heavy inhalation exposure to this substance and no conclusive solid evidence is accessible in this regard.

This study is, therefore, carried out with the following objectives:

1) To assess the degree to which workers of a gypsum production plant are exposed to gypsum dust;

2) To determine the prevalence of respiratory symptoms, if any, among workers who are exposed to gypsum dust as compared with a non-exposed referent population;

3) To ascertain if gypsum dust induces any significant changes in the parameters of ventilatory function.

\section{Materials and Methods}

\subsection{Subjects and Study Design}

This cross-sectional study was carried out at a local gypsum producing plant in Shiraz, capital of Fars province in Iran. All subjects (20 males) with a history of past and present exposure to gypsum dust were investigated. Simultaneously, 20 healthy non-exposed males, with similar demographic characteristics, were chosen from clerical stuff of an educational center by simple random sampling technique and served as the referent group.

All subjects voluntarily participated in the study. The study was performed in accordance with the Helsinki Declaration of 1964 as revised in 2007 [19].

\subsection{Measurements of Investigated Variables}

\subsubsection{Respiratory Illness}

Subjects were interviewed and respiratory symptom questionnaire, as suggested by the American Thoracic Society [20], were filled out for them. The questionnaire contained questions concerning respiratory symptoms such as cough, wheezing and dyspnea, smoking habits, occupational history, preexisting medical conditions and family history of each employee. 
Prevalence of symptoms of respiratory diseases was then calculated from the data extracted from the completed questionnaires.

\subsubsection{Ventilatory Function Tests}

Ventilatory function tests were performed on site, using a portable calibrated ST-150 spirometer analyzer (Fukuda Sangyo Inc. Japan) according to the guidelines of the American Thoracic Society [21]. For evaluation of cross shift changes, ventilatory function tests were measured twice for the exposed workers (after a 48 hour exposure free period (before shift) and at the end of the work shift (post-shift)) and once for the unexposed employees. Ventilatory parameters included mean percentage predicted Vital Capacity (VC), Forced Vital Capacity (FVC), Forced Expiratory Volume in the 1st second (FEV1) and Peak Expiratory Flow (PEF). Spirometer was calibrated, at least twice a day, with a 3-liter syringe in accordance with the spirometer manufacturer's standard protocol. Detailed information regarding ventilatory function tests is to be found in other publications of the authors [22].

\subsubsection{Measurement of Atmospheric Concentrations of Gypsum Dust}

To assess the extent to which workers were exposed to gypsum dust, using NIOSH method [23], its atmospheric concentrations (respirable and inhalable dust fractions) were determined in three work areas, and the mean airborne concentration was expressed in $\mathrm{mg} / \mathrm{m}^{3}$. Air samples were collected using personal dust samplers (Casella, London, UK) equipped with cyclone and a Millipore PVC membrane filters ( $5 \mu \mathrm{m}$ pores) in order to separate respirable and inhalable fractions. Pretest experiments showed that the appropriate sampling time was about 120 min.

\subsection{Data Analysis and Statistical Procedures}

Student's $t$-test, chi-squared, Fisher's exact test, logistic and multiple linear regression analyses were used to analyze the data. In all the statistical comparisons, a $p$-value of less than 0.05 was considered significant. Statistical tests were conducted using SPSS V19.0 on a personal computer.

\section{Results}

The average (mean $\pm \mathrm{SD}$ ) age $(\mathrm{yr})$, BMI $\left(\mathrm{kg} / \mathrm{m}^{2}\right)$, duration of exposure (length of employment for referent subjects), (yr) and number of cigarettes smoked and airborne concentrations of gypsum dust $\left(\mathrm{mg} / \mathrm{m}^{3}\right)$ are presented in Table 1. As shown, no significant differences were noted between exposed and non-exposed subjects as far as confounding variables were concerned. Additionally, the mean atmospheric concentration of gypsum dust was higher than the current TLV value of $10 \mathrm{mg} / \mathrm{m}^{3}$ [24].

Prevalence rates of respiratory symptoms are shown in Table 2. As shown, symptoms such as phlegm, wheezing and dyspnea were significantly more common among exposed individuals. The parameters of ventilatory function were also measured for both groups. Table 3 presents predicted percentages of VC, FVC, FEV1, FEV1/FVC ratio and PEF. The results showed that exposure to gypsum dust was associated with significant

Table 1. Comparison of demographic variables, smoking habits and level of exposure to gypsum dust.

\begin{tabular}{|c|c|c|c|}
\hline Variable & Exposed $(n=20)$ & Non-Exposed $(n=20)$ & $P$-Value \\
\hline Age (mean \pm SD, yr) & $37.70 \pm 9.69$ & $42.15 \pm 11.25$ & $0.188^{\dagger}$ \\
\hline BMI (mean $\left.\pm \mathrm{SD}, \mathrm{kg} / \mathrm{m}^{2}\right)$ & $25.12 \pm 4.24$ & $25.33 \pm 3.57$ & $0.968^{\dagger}$ \\
\hline Length of exposure/employment (mean \pm SD, yr) & $12.25 \pm 7.08$ & $10.30 \pm 9.41$ & $0.46^{\dagger}$ \\
\hline No. (\%) smokers & $3(10 \%)$ & $4(20 \%)$ & $0.33^{\dagger \dagger}$ \\
\hline Number of cigarettes smoked per day (mean \pm SD) & $12.50 \pm 3.53$ & $11.50 \pm 9.25$ & $0.89^{\dagger}$ \\
\hline Length of smoking (mean \pm SD, yr) & $14 \pm 11$ & $22 \pm 9.32$ & $0.36^{\dagger}$ \\
\hline Respirable concentration of gypsum dust $\left(\mathrm{mg} / \mathrm{m}^{3}\right)(\text { mean } \pm \mathrm{SD})^{\ddagger}$ & $15.80 \pm 11.83$ & N/A & N/A \\
\hline Inhalable concentration of gypsum dust $\left(\mathrm{mg} / \mathrm{m}^{3}\right)(\text { mean } \pm \mathrm{SD})^{\ddagger}$ & $24 \pm 14.76$ & N/A & N/A \\
\hline
\end{tabular}

Notes: BMI = body mass index (kilograms per square meters); ${ }^{\dagger}=$ independent sample $t$ test, ${ }^{\dagger+}=\chi^{2}$ or Fisher’s exact test. ${ }^{\ddagger}$ Number of air samples $=9$. 
cross shift decrements in FEV1, FVC and FEV1/FVC ratio. Additionally, some post shift parameters of ventilatory function were significantly lower than those of non-exposed subjects $(p<0.05)$. Conversely, no significant differences were noted between the pre-shift ventilatory function tests values of exposed subjects as compared to referent individuals.

The association between exposure to gypsum dust and the prevalence of respiratory symptoms is displayed in Table 4. Logistic linear regression analysis showed that after adjusting for important confounders (i.e. age, BMI and smoking habits) there was statistically significant association between exposure to gypsum dust with the prevalence of phlegm, wheezing, and dyspnea $(p<0.05)$.

Similarly, association between exposure to gypsum dust and changes in the parameters of ventilatory function is displayed in Table 5. The results of statistical analysis revealed that after adjusting for age, BMI and smoking habits, there were significant associations between exposure to gypsum dust with FVC and FEV1, in that exposure to gypsum dust resulted in an average of $\sim 7$ units of decrement in these parameters.

Table 2. Frequency of respiratory symptoms among exposed and non-exposed subjects (\%).

\begin{tabular}{cccc}
\hline Symptoms & Exposed $(n=20)$ No (\%) & Non-Exposed $(n=20)$ No (\%) & $P$-Value \\
\hline Cough & $7(35 \%)$ & $2(10 \%)$ & 0.064 \\
Phlegm & $10(50 \%)$ & $3(15 \%)$ & $0.02^{*}$ \\
Productive cough & $3(15 \%)$ & $1(5 \%)$ & 0.3 \\
Wheezing & $8(40 \%)$ & $1(5 \%)$ & $0.01^{*}$ \\
Dyspnea & $13(65 \%)$ & $6(30 \%)$ & $0.028^{*}$ \\
\hline
\end{tabular}

${ }^{\dagger}$ Chi-squared or Fisher's exact test, "Significantly different from its corresponding value for the non-exposed group.

Table 3. Percentage predicted lung function among exposed and non-exposed subjects.

\begin{tabular}{|c|c|c|c|c|c|c|}
\hline \multirow{2}{*}{ Parameters } & \multicolumn{2}{|c|}{ Exposed $(n=20)$} & \multirow{2}{*}{$\begin{array}{l}\text { Non-Exposed } \\
\quad(n=20)\end{array}$} & \multirow{2}{*}{$\begin{array}{c}P \text {-Value } \\
\text { Pre-Shift vs. } \\
\text { Post-Shift }^{\dagger}\end{array}$} & \multirow{2}{*}{$\begin{array}{c}P \text {-Value } \\
\text { Pre-Shift vs. } \\
\text { Non-Exposed }^{++}\end{array}$} & \multirow{2}{*}{$\begin{array}{c}P \text {-Value } \\
\text { Post-Shift vs. } \\
\text { Non-Exposed }^{\dagger+}\end{array}$} \\
\hline & Pre-Shift & Post-Shift & & & & \\
\hline VC & $91.4 \pm 11.16$ & $91.5 \pm 12.12$ & $94.7 \pm 15.17$ & 0.88 & 0.18 & 0.18 \\
\hline FVC & $95.75 \pm 12.6$ & $85.15 \pm 11.88$ & $96 \pm 14.74$ & 0.009 & 0.39 & $0.015^{*}$ \\
\hline FEV1 & $92.65 \pm 11.59$ & $89.1 \pm 11.76$ & $96.8 \pm 11.18$ & 0.023 & 0.12 & $0.013^{*}$ \\
\hline FEV1/VC & $101.7 \pm 9$ & $98.68 \pm 12.6$ & $103.36 \pm 10.17$ & 0.28 & 0.33 & 0.07 \\
\hline FEV1/FVC & $97.26 \pm 9.24$ & $101.41 \pm 8.08$ & $101.63 \pm 7.4$ & 0.032 & 0.09 & 0.45 \\
\hline PEF & $93.25 \pm 21.28$ & $89.9 \pm 23.49$ & $87.6 \pm 21.73$ & 0.41 & 0.24 & 0.46 \\
\hline
\end{tabular}

${ }^{\dagger}$ Paired $t$-test, ${ }^{\dagger \dagger}$ Significantly different from non-exposed values (independent $t$-test), ${ }^{*}$ Significantly different from its corresponding value for the non-exposed group.

Table 4. Association between exposure to gypsum dust and prevalence of respiratory symptoms ${ }^{\dagger}$.

\begin{tabular}{cccc}
\hline Outcome & $\beta$ & Odds Ratio & $P$-Value \\
\hline Cough & 1.29 & 5.4 & 0.07 \\
Phlegm & 1.73 & 5.6 & 0.024 \\
Productive cough & 0.78 & 2.19 & 0.53 \\
Wheezing & 2.53 & 12.66 & 0.024 \\
Dyspnea & 1.94 & 6.96 & 0.013 \\
\hline
\end{tabular}

\footnotetext{
${ }^{\dagger \dagger}$ Binary logistic regression.
} 
Table 5. Association between exposure to gypsum dust and changes in the parameters of ventilatory function ${ }^{\dagger}$.

\begin{tabular}{cccc}
\hline Parameters & B & SE & $P$-Value \\
\hline VC & -2.85 & 3.95 & 0.47 \\
FVC & -7.51 & 3.8 & 0.05 \\
FEV1 & -7.4 & 3.22 & 0.028 \\
FEV1/VC & -0.32 & 2.59 & 0.9 \\
FEV1/FVC & -5.69 & 3.62 & 0.1 \\
PEF & 0.38 & 7.64 & 0.9 \\
\hline
\end{tabular}

${ }^{\dagger}$ Multiple linear regression model, B: Average units of decrement in each parameter of ventilatory function of exposed subjects compared to their unexposed counterparts, SE: Standard error.

\section{Discussion}

This study was undertaken to investigate the respiratory effects of long-term occupational inhalation exposure to high concentrations of calcium sulfate dust.

Subjects were exposed to gypsum dust at a concentration that exceeded its current threshold limit value (TLV) of $10 \mathrm{mg} / \mathrm{m}^{3}$.

Given the data provided, both groups were similar as far as demographic variables were concerned (Table 1). None of the subjects had past medical or family history of respiratory illnesses or any other chest operations or injuries. Given the above, and the fact that all important confounders were controlled and accounted for in this study, an increased prevalence of respiratory symptoms (phlegm, wheezing and dyspnea) along with significantly reduced lung functional capacities (FVC and FEV1) may well be explained by exposure to gypsum dust. When smokers of both groups were separated and the data of non-smokers were reanalyzed, similar results were obtained, indicating that the findings of the study are independent from the role of smoking as a confounder. The results of linear and logistic regression analyses provided further support for this proposition.

Prevalence of respiratory symptoms was significantly higher in exposed group (Table 2) which is consistent with the results of other studies in which phlegm and dyspnea [25], irritation of mucous membranes and upper respiratory tract [8] [10] cough, sneeze and runny nose [5] have been reported as a result of y exposure to gypsum dust.

Similarly, acute exposure to dust concentrations in excess of the PEL/TLV has been shown to result in coughing, dyspnea, wheezing, general irritation of the nose, throat, and upper respiratory tract, and impaired ventilatory function [26].

To the best of authors' knowledge, the distinction between possible short (acute) and long (chronic) respiratory effects of exposure to gypsum dust in comparison with an appropriate referent group has not been investigated earlier. In the present study, in order to differentiate between these effects, spirometery was conducted prior to and after exposure to gypsum dust.

As shown in Table 3, significant decrements were noted in most parameters of ventilatory function after exposure. These results are thought to support the hypothesis that exposure to gypsum dust induces acute adverse effects over the course of a work shift. Similarly, most post-shift parameters of ventilatory function of exposed subjects were lower than those of referent individuals and the differences were significant for FVC and FEV1. In contrast, preshift values were not significantly different from those of referent subjects.

These findings provide additional evidence to support the contention that exposure to gypsum dust is associated with acute reversible ventilatory disorders. These conclusions are also further supported by the results of Table 5, which showed that after adjusting for important confounders, significant associations were present between decrements in some parameters of ventilatory function and exposure to gypsum dust.

Interestingly, no significant differences were noted between preshift parameters of ventilatory function with those of the referent group. This observation provides circumstantial evidence to support the notion that under the exposure scenario of this study in terms of severity and length of exposure, gypsum dust does not induce chronic irreversible effects on lungs' functional capacities.

These findings are in line with the results of some other previous studies. For instance, Burilkov did not find 
any lung diseases from exposure to natural gypsum dust unless in the presence of silica [27]. Similar findings have been reported by others [14] [15].

Absence of any chronic respiratory disorders as a result of exposure to gypsum dust may be explained, at least in part, by the fact that gypsum dust due to its high solubility and thus very short half-life [27] [28] is rapidly cleared from the lungs via dissolution and mechanisms of particle clearance [29]. It has also been emphasized that reported chronic lung diseases attributed to gypsum dust may have been related to its silica impurities [13] [15] [16] [27] [30].

A cause and effect relationship cannot be established from cross-sectional studies, such as the present study.

Therefore, due to this inherent limitation, our findings might be viewed with certain degree of skepticism and interpreted tentatively. While the authors agree with this view, they reiterate that the following few lines of circumstantial evidence indicate that their findings are very likely to be the results of exposure to gypsum dust:

First, the exposed subjects, when employed, were free from any preexisting medical conditions, particularly those involving respiratory symptoms.

Second, apart from gypsum dust, the exposed individuals had no history of exposure to other chemicals known to cause respiratory disorders prior to their employment in the plant or during the course of their employment, thereafter.

Third, changes occurred during a work shift following exposure to gypsum dust, and were reversible, once exposure ceased.

Fourth, after adjusting for important confounders, significant associations observed between exposure to gypsum dust and the prevalence of respiratory symptoms and reduced ventilatory capacities.

Fifth, similar findings were found when the data of non-smokers were analyzed.

\section{Conclusions}

Our findings showed that occupational exposure to high concentrations of gypsum dust was associated with a significant increase in the prevalence of respiratory symptoms and significant acute reversible decrements in some parameters of ventilatory function.

To reduce workers' exposure to gypsum dust, engineering controls such as local exhaust ventilation systems, administrative measures and/or the use of personal protective equipment are recommended.

Additional follow up epidemiological studies with larger sample sizes and sufficiently long follow ups are thought to be absolutely necessary and sensible to further confirm these initial observations and to assess possible ramifications of long-term exposure to high concentrations of gypsum dust.

\section{Acknowledgements}

Funding through Shiraz University of Medical Sciences, Vice Chancellor for Research Affairs, grant No. 9334 partially supported these investigations. The authors also wish to sincerely thank Dr. Hassanzadeh, professor of clinical epidemiology, for his assistance in logistic and linear regression analyses of the data.

\section{References}

[1] Reed, A.H. (1975) Gypsum. By the Staff, Mineral Facts and Problems, Vol. 667, Bureau of Mines, Washington, 469477.

[2] Stellman, J.M. (1998) Chemicals; Industries and occupations, in Encyclopedia of Occupational Health and Safety. Chapter 62, Intemational Labour Organization, Geneva.

[3] TOXNET (2005) Calcium Sulphate Dihydrate.

[4] Baxter, P.J., et al. (2010) Other Non-Fibrous Mineral Dust, in Hunter's Diseases of Occupations. Taylor and Francis Group, CRC Press, London, 1324.

[5] NIOSH (2005) Undated-C. NPGD0308-NIOSH Pocket Guide to Chemical Hazards. Gypsum [CAS 13397-24-5]. http://www.cdc.gov/niosh/npg/npgd0308.html

[6] Collis, E.L. (1931) Occupational Dust Diseases, Bull. Hyg.: Lond.

[7] (2006) Chemical Information Review Document for Synthetic and Naturally Mined Gypsum (Calcium Sulfate Dihydrate) [CAS No. 13397-24-5], I. Integrated Laboratory Systems, N. Research Triangle Park, and U.C.N. N01-ES35515, Editors. National Toxicology Program. 
[8] Bethesda, M. (1991) The Hazardous Substances Data Bank: Calcium Sulfate. N. L. O. Medicine [NLM].

[9] Genium (1990) Material Safety Data Sheet. G.P. Corporation, Schenectady.

[10] Parmeggiani, L. (1983) Encyclopedia of Occupational Health and Safety. 3rd Edition, Geneva, International Labour Organization (ILO).

[11] TOXNET (1989) Calcium Sulphate. http://www.toxnet.nlm.nih.gov

[12] Gordon, B.L., et al. (Eds.) Clinical Cardiopulmonary Physiology. In: Gordon, B.L. and Kory, R.C., Eds., Clinical Cardiopulmonary Physiology, Grune \& Stratton, New York, 350.

[13] Voropaev, A.A. (1967) Major Problems of Industrial Hygiene in Production of Construction Gypsum (Hygienic, Clinical and Experimental Investigations). Gigiena Truda i Professional'nye Zabolevaniia, 11, 23-26.

[14] Feil, A. (1951) Cement Dust and Pulmonary Tuberculosis. Le Médecin d'Usine; Revue d'Hygiène Industrielle et des Maladies Professionnelles, 13, 272.

[15] Gardner, L.U. (1934) Silicosis and Its Relationship to Tuberculosis. American Review of Tuberculosis, 29, 1-7.

[16] Oakes, D., Douglas, R., Knight, K., Wusteman, M. and McDonald, J.C. (1982) Respiratory Effects of Prolonged Exposure to Gypsum Dust. The Annals of Occupational Hygiene, 26, 833-840. http://dx.doi.org/10.1093/annhyg/26.8.833

[17] Minstry of Industry (2012) Mining and Trade. www.mimt.gov.ir/

[18] Sanaei, G.H. Industrial Toxicology. Vol. 1. 1385: Tehran University, Tehran.

[19] World Medical Association Declaration of Helsinki: Ethical Principles for Medical Research Involving Human Subjects. Adopted by the 18th General Assembly, Helsinki, June 1964. http://www.wma.net/en/30publications/10policies/b3/17c.pdf

[20] Ferris, B.G. (1978) Epidemiology Standardization Project (American Thoracic Society). The American Review of Respiratory Disease, 118, 1-120.

[21] American Thoracic Society (1979) ATS Statement-Snowbird Workshop on Standardization of Spirometry. The American Review of Respiratory Disease, 119, 831-880.

[22] Neghab, M., HabibiMohraz, M. and Hassanzadeh, J. (2011) Symptoms of Respiratory Disease and Lung Functional Impairment Associated with Occupational Inhalation Exposure to Carbon Black Dust. Occupational Health, 53, 432438. http://dx.doi.org/10.1539/joh.11-0083-OA

[23] NIOSH (1984) Nuisance Dust, Respirable: Method 0600. Department of Health and Human Services, Public Health Service, Centers for Disease Control, National Institute for Occupational Safety and Health[NIOSH], Cincinnati, 84100.

[24] American Conference of Governmental Industrial Hygienists (ACGIH) (2009) Threshold Limit Values for Chemical Substances and Physical Agents and Biological Exposure Indices. ACGIH, Cincinnati.

[25] Ghasemkhani, M., Kumashiro, M., Rezaei, M., Anvari, A.R., Mazloumi, A. and Sadeghipour, H.R. (2006) Prevalence of Respiratory Symptoms among Workers in Industries of South Tehran, Iran. Industrial Health, 44, 218-224. http://dx.doi.org/10.2486/indhealth.44.218

[26] (2013) Miscellaneous Gypsum Products. National Gypsum Company, Charlotte.

[27] Burilkov, T. and Michailova-Dotschewa, L. (1990) Dangers of Exposure to Dust Extraction and Production of Natural Gypsum. Wiss Umwelt, 2, 89-91. Abstract from EMBASE 91094689.

[28] Einbrodt, H.J. (1988) The Health Risks by Dusts of Calcium Sulfate (Ger.). Wiss Umwelt, 4, 179-181. Abstract from EMBASE 89261036.

[29] Clouter, A., Houghton, C.E., Bowskill, C.A., Hoskins, J.A. and Brown, R.C. (1996) An in Vitro/in Vivo Study into the Short-Term Effects of Exposure to Mineral Fibers. Experimental and Toxicologic Pathology, 48, 484-486. http://dx.doi.org/10.1016/S0940-2993(96)80061-3

[30] Ramazzini, B. (1703) De morbis artificum diatriba. 2nd Edition, Guilielmus van de Water, Ultrajecti, 62. 